Comfort in the Indoor Environment: A Theoretical Framework Linking Energy Efficiency and Universal Design

Peer-reviewed author version

KAPEDANI, Ermal; HERSSENS, Jasmien \& VERBEECK, Griet (2018) Comfort in the Indoor Environment: A Theoretical Framework Linking Energy Efficiency and Universal Design. In: Di Bucchianico, G.; Kercher, P. F. (Ed.). Advances in Design for Inclusion: Proceedings of the AHFE 2017 International Conference on Design for Inclusion, Springer,p. 303-313.

DOI: $10.1007 / 978-3-319-60597-5 \_28$

Handle: http://hdl.handle.net/1942/24943 


\title{
Comfort in the Indoor Environment: A Theoretical Framework Linking Energy Efficiency and Universal Design
}

\author{
Ermal Kapedani ${ }^{1}$, Jasmien Herssens ${ }^{1}$, Griet Verbeeck ${ }^{1}$ \\ ${ }^{1}$ Hasselt University, Faculty of Architecture and Art, Agoralaan, Gebouw D, \\ 3590 Diepenbeek, Belgium \\ (ermal.kapedani, jasmien.herssens, griet.verbeeck)@uhasselt.be
}

\begin{abstract}
Energy Efficiency (EE) and Universal Design (UD) are two topics high on governmental policy and research agendas which have been considered separately both in research and practice. This research hypothesizes that comfort can be a conceptual link that can represent both EE and UD features. In order to understand the broader meaning of comfort at home from the perspective of inhabitants in the context of home renovations, and to test our hypothesis, we conducted 3 qualitative studies with different user groups. The results confirm that users associate with comfort all aspects related to $\mathrm{EE}$ as well as with most aspects in UD. In addition, results indicate that EE can be an integral part of UD if both are considered from a comfort point of view. These are presented in a theoretical framework for comfort that can be used to further study a potential integration of the EE and UD fields.
\end{abstract}

Keywords: Comfort $\cdot$ Energy efficiency $\cdot$ Universal design $\cdot$ Home $\cdot$ Renovation

\section{Introduction - Why talk about Comfort?}

This paper brings together the policy and research agendas of Universal Design (UD) and energy efficiency (EE) in buildings, which have until very recently advanced along separate paths. As part of the drive for greater sustainability in the building stock, public policy and societal objectives aim for higher numbers of housing renovations that accommodate lifelong living and significantly increase energy efficiency.

The combination of EE and UD holds potential for creating home renovation concepts which are faster, offer more value and less inconvenience to homeowners. However, the nature of these two concepts in theory and practice makes their merger problematic and demands a third, bridging concept [1].

Moreover, there is a misalignment of objectives between policy and societal objectives for greater application of EE and UD in home renovations and the individual objectives of homeowners when planning home renovations. People are more concerned with the perceived result of measures on them individually, rather than the effect of measures on society. Personal comfort appears to be a key factor. 
Studies in several European countries have shown that the non-energy benefits are important motivators for homeowners when considering renovation measures for their homes [2, 3]. In literature comfort is an often repeating criterion or motivation for adoption of EE measures. Both, the SEREC [4] and COHERENO [5] research projects identify improvement in comfort as an important motivator for energy efficiency renovations in Belgium. Shove [6], Lindén, Carlsson-Kanyama [7], and Aune, Ryghaug [8] point out that policy instruments must be in direct conversation with cultural preferences, particularly regarding concepts like comfort and convenience.

So far there is little field research on the drivers behind UD renovations or adoption. However, comfort is itself one of 8 goals of UD [9]. An increase in comfort of access and use are logical motivations for adoption of UD features, especially for people with disabilities. For example, manufacturers and designers of kitchens and bathrooms are already aware that their products should not be marketed based on a current or expected disability but rather on their "thoughtful design" features of safety, function and aesthetics [10].

Comfort appears to be a common ground between UD and EE. On this basis we hypothesize that comfort is popular driver for home renovations that can be a conceptual link which encompasses UD and EE aspects. The research in this paper was guided by the question: How can comfort be conceptualized as a merger of UD and EE?

Explicit and implicit meanings Energy Efficiency and Universal Design are examined as part of our analysis. However, it is not the intention of this paper to open a debate or evaluation on the meaning or terminology of these terms, particularly in the case of Universal Design which is still a contested concept. The meanings of these terms must also be tapered by the scope of this paper which focuses on private homes, rather than public buildings or product design.

The next section provides a literature overview which underlines the broad, complex and contested meanings of comfort in EE, UD and other research fields. The literature discussion is followed by studies which explore the meaning of comfort for residents in the context of home renovations.

\section{Comfort in literature}

Rybczynski [11] tracks the evolution of comfort from original Latin as consoling spiritually; to a sense of intimacy; then domesticity; pleasure and ease in $18^{\text {th }}$ century; light air and warmth in Victorian times; efficiency and convenience in early $20^{\text {th }}$ century; and as austerity during modernism. His historical account brings out the culturally dependent and constantly changing nature of comfort as well as a trajectory that moves from a social and human focus towards a building and technology focus.

Shove et al. [12] have duly pointed out that energy is only a means to an end, so when we discuss energy efficiency we need to keep in mind its purpose. In buildings the primary purpose of energy use is to maintain required indoor environmental quality (IEQ). In EE studies IEQ includes four indicators: thermal comfort, visual comfort, acoustic comfort and good air quality $[13,14]$. In other words an energy efficient building is one that provides the same level of comfort conditions (thermal, lighting, acoustic, and air quality) using less energy. Comfort is most often understood narrowly 
as the technically defined parameter of "thermal comfort" and sometimes includes other IEQ parameters such as indoor air quality or acoustic comfort.

These four indicators certainly contribute to IEQ at home. However, several studies [14-18] suggest that other non-EE factors, such as spatial and design related ones, also influence satisfaction with the indoor environment. The design aspects fall within the guidelines for Lifelong-living (Lifetime Homes in UK). LLL guidelines are often considered a practical and physical manifestation of the principles of UD [19].

In UD literature the term comfort is used in the context of accessibility or usability. It most prominently used as one of eight goals of UD where Steinfeld \& Maisel [9] define it as dealing with biomechanics. As in EE literature, UD scholars apply comfort as a, sometimes subjective, physiological concept. The precise definition and even the term of UD varies somewhat but most definitions generally aim to "improve product experience across a broad range of users"[20] where products include buildings and services. The central objective of Universal Design is to improve the quality of buildings for all. While some goals of UD (e.g. social integration, cultural appropriateness) go beyond physical objects, many (e.g. body fit, awareness, personalization, wellness etc.) are intuitively linked to spatial and design aspects of a building. Therefore, we argue that comfort is an implicit overall objective of UD.

However, comfort is a term with very diverse, and often broad, meanings in many research fields. In the health sciences, and nursing in particular, which are quite concerned with comfort, it is defined either as a state of its own or as a relief from discomfort, i.e. comfort is only perceived when discomfort is removed through an intervention with time as a critical component [21, 22]. In this sense comfort is measured as relative to a previous state, not an absolute quantity.

In a broad sense comfort can be interpreted as a "self-conscious satisfaction with the relationship between one's body and the immediate environment" (Crowley, 2001, p. 142). This definition encompasses the full physiological range of senses and is much wider than the term commonly used in EE and UD literature.

Chappells and Shove (2005) argue that comfort covers a much wider range of physiological possibilities than currently contemplated by energy and environmental policy makers, and that the concept of comfort itself is malleable and in constant change. They warn that narrow definitions of comfort risk getting us stuck into "social and technical trajectories that are ultimately unsustainable" [23]. Shove [24] represents comfort as a one directional ratchet-like path dependency. Cole et al. [25] go further to include social, psychological, cultural and contextual aspects into comfort.

The following section helps to build a clearer picture of the multidimensional nature of comfort in the context of home renovations and the indoor environment from the perspective of residents. As a result, in section 4, a list of comfort indicators is developed and we propose a framework which uses comfort in the indoor environment as conceptual link between EE and UD for application in the residential context.

\section{Comfort from residents' perspective}

The set of studies described below aims at revealing the meaning of comfort in the context of housing renovations for a range of groups - UD professionals, home owners, 
and (inexperienced) architecture students - in their capacity as residents and owners of their homes.

The three qualitative studies were exploratory and each was carried out in different contexts and with different procedures. The details are described below. The data gathered was analyzed similarly in all three studies. A general understanding of thoughts and opinions expressed by participants was summarized by extracting the descriptive terms used to describe comfort. These are represented as a conventional list as well as visually as word clouds.

\subsection{Study 1 - Include2015 workshop}

At Include 2015 conference a workshop was carried out with 36 participants, who are professionals considered as experts in UD. The purpose of the workshop was to elicit an understanding of comfort at home, using people's own words and to check and compare the overlap with terms commonly used in Universal Design. The participants, were divided randomly in six groups and answered the question: What would your home look like if it was changed into a home focused on comfort? First the participants discussed within their groups and then presented and discussed their results with all the workshop participants.

Over the 6 groups the concept of "comfort" at home consistently brought up the terms that are the focus of UD as well as EE renovations. These included "indoor climate", "accessibility", "usability", "lighting", "flexibility" etc. The full list of terms per group is shown below (Figure 1).

$\begin{array}{llllll}\text { Group 1: } & \text { Group 2: } & \text { Group 3: } & \text { Group 4: } & \text { Group 5: } & \text { Group 6: } \\ \text { Access } & \text { Built (accessibility, } & \text { Usability } & \text { Adaptability } & \text { Materials } & \text { Accessibility } \\ \text { Rest } & \text { usability) } & \text { Light } & \text { Personalization } & \text { Temperature } & \text { Climate } \\ \text { (usability/coziness) } & \text { Natural (Thermal, } & \text { Personalization } & \text { Cleanliness } & \text { Simplicity } & \text { Sensory } \\ \text { Temperature } & \text { Lighting, Sensory) } & \text { Intimacy/pleasure } & \text { Sensory } & \text { Outdoors } & \text { Light } \\ \text { Sensory } & \text { Proximity (urban } & \text { Accessibility } & \text { Social } & \text { Lighting } & \text { Noise } \\ \text { Lighting } & \text { level) } & \text { Fresh air } & \text { Sustainable } & \text { Peaceful } & \text { Social } \\ \text { Entertainment } & \text { Social } & \text { Atmosphere } & \text { (energy + } & \text { (noise) } & \text { Privacy } \\ \text { (sociability, } & \text { Socio-functional } & \text { (sensory, thermal) } & \text { materials) } & \text { Welcoming } & \text { Safety \& } \\ \text { usability) } & & \text { Wellbeing } & & \text { (Social, } & \text { Security } \\ \text { Inside-out spaces } & & \text { Safety } & & \text { accessible) } & \text { Virtuality } \\ & & & & & \text { Maintenance }\end{array}$

Fig 1. List of topics describing comfort in each group of participants. Accessibility, temperature and social topics are mentioned by all 6 groups.

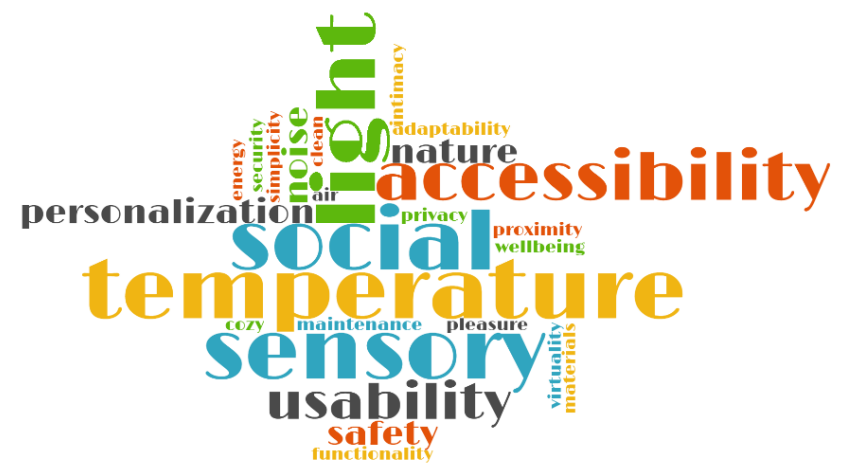

Fig 2. Word cloud of comfort related topics mentioned in the Include 2015 workshop. 
Figure 2 shows a word cloud of the themes mentioned in the workshop. The size of the font corresponds to the frequency of the term's mentions. We can see that participants considered temperature, light, social and sensory aspects to be most important. These were followed by accessibility and usability.

\subsection{Study 2}

This study was part of a course where master students in architecture at Hasselt University, Belgium, developed design interventions for renovation of 10 pre-1980 single family homes into modern Nearly Zero Energy homes. The design task required the incorporation of comfort from the owners' perspective.

The students performed a three-part semi-structured interview with home owners to elicit owners' understanding of comfort and their specific needs for the renovation. The students first gathered basic demographic information. Then they asked the owners "What would you change or keep in order to make your home more focused on comfort?" without prompting and without offering a definition of comfort. Finally they walked around the house, space by space, and asked the residents what they liked or wanted changed in each area. During the walkthrough they used comfort-related topics as prompts during the walkthrough which were based on the results from Study 1, the Include 2015 workshop.

The keywords used by the home owners to describe comfort are compared with the key words used to describe renovation needs and desires during the walkthrough. Their respective word-frequency clouds are shown below (Figure $3 \& 4$ ).
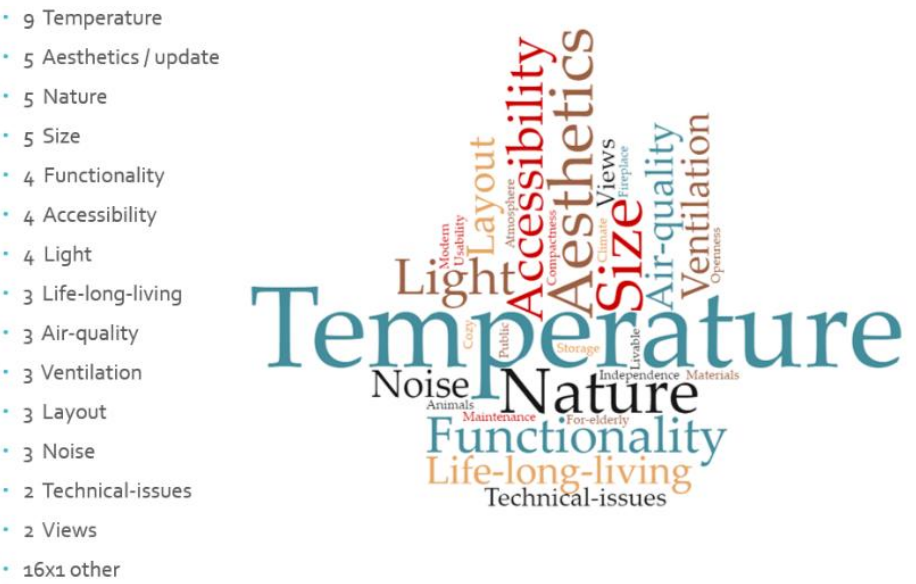

Fig 3. Word cloud of unprompted terms used to describe comfort by homeowners. $N=10$ 

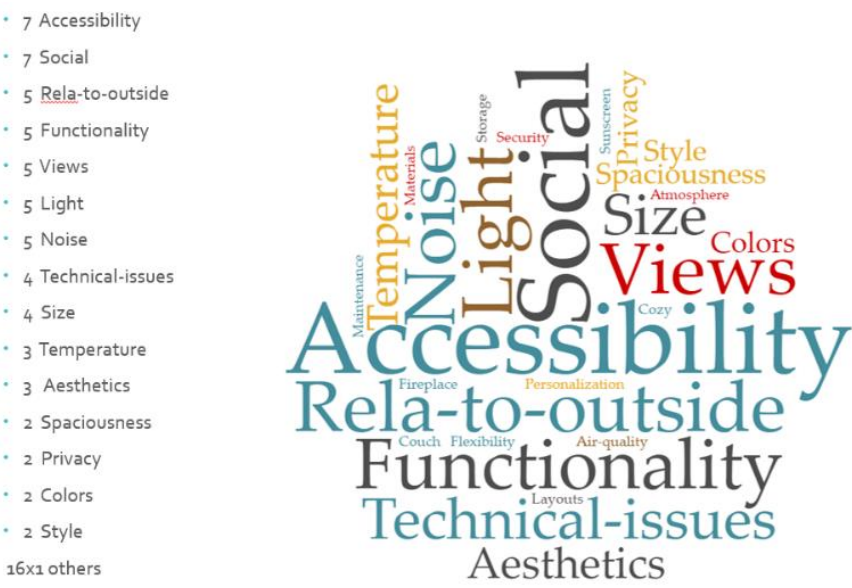

Fig 4. Word cloud of topics discussed to describe comfort during the walk through the house.

\subsection{Study 3 - Students}

The survey involved 57 interior architecture students studies at bachelor level. They were asked to reflect on a space in their house that they considered comfortable and describe what made it so in a few words (maximum 1 paragraph).

The word-cloud and list (Figure 11) shows the resulting frequency with which each of the terms was mentioned. There is a clear group of four terms that are most often mentioned: peaceful, warmth (temperature), light, and cozy. Twelve other terms were mentioned between five and 12 times, and another 49 terms were mentioned by three or fewer students.

$$
\begin{array}{llll}
\cdot 28 & \text { peaceful } & \cdot 12 & \text { soft } \\
\cdot 26 & \text { warmth } & \cdot 10 & \text { furniture } \\
\cdot 20 & \text { light } & \cdot 8 & \text { relaxing } \\
\cdot 19 & \text { cozy } & \cdot 8 & \text { domestic } \\
& & 7 & \text { spacious } \\
& \cdot 7 & \text { open } \\
& \cdot 6 & \text { personal } \\
& \cdot 6 & \text { inviting } \\
& \cdot 6 & \text { simplicity } \\
& \cdot 6 & \text { color } \\
& & \text { material } \\
& & & \text { mood-lighting } \\
& & \\
& &
\end{array}
$$

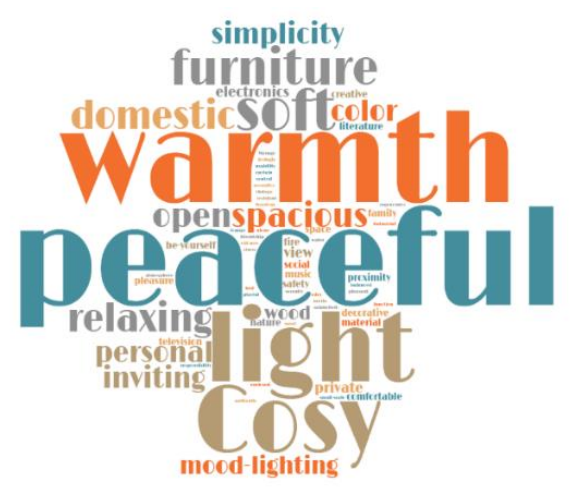

Fig 5. Word cloud and frequency of terms describing comfort by architecture students. $N=57$ 


\subsection{Discussion of Studies}

In Study 1 often the more concrete terms, such as temperature, were mentioned under "softer" themes such as "sensory", "atmosphere", and "social". "Social" was a theme mentioned by all groups and is a reminder that comfort at home extends beyond physical aspects. This is something that is only discussed in socio-technical studies in EE (eg. Gram-Hanssen [26], Aune [27], Tweed [28]). When discussing, for example, accessibility or temperature we should keep in mind their relation to social activity at home.

During the discussion there was general agreement that even for "us" the professionals, in the context of changing our own home, talking about comfort was "easier" than talking about the outcome of Universal Design, while it seems to include many of the same topics and without the stigmatization that is sometimes associated with UD.

The second study, with homeowners considering a renovation, it appears that in the first part of the interview (unprompted) a more "gut-feeling" meaning of comfort is produced. Instead the walkthrough might reveal a more "practical" understanding of comfort aspects. For example, there is a switch in importance for the keywords "temperature" (i.e. warmth) and "accessibility". It seems that issues of accessibility became more apparent once people were moving around the house and thinking about the spaces.

Overall, it can be noted that in both parts of the interview, prompted and unprompted, the terms used to describe comfort were similar to each other as well as to the terms used at the Include 2015 workshop.

In the third study the most mentioned terms are similar to the top terms mentioned in the first two studies. They are also similar in the sense that these terms represent both practical/measurable aspects as well as softer, more difficult to define and measure aspects but which nonetheless significantly contribute to comfort at home. Overall, most $(2 / 3)$ of the top 15 terms used refer to experiential aspects rather than technical or functional ones. This tendency is stronger than in the previous two studies.

\section{A Framework for Linking EE and UD}

\subsection{Comfort Indicators}

The results above reveal that residents associate with comfort at home all indicators related to EE such as temperature, air quality, light and noise, as well as with LLL indicators such as usability, accessibility, views to outdoors etc.. The keywords mentioned in these studies corroborate results from a study by Frontczak, Andersen [16] which found that people mentioned light, temperature, air and noise as important for comfort but also social and spatial aspects such as nature, view, size of room and style.

In effect, these indicators are partly describing the quality of environment at home. Therefore, in order to form a well-structured list of comfort indicators we consulted examples of building quality assessment with a holistic approach in literature on comfort, UD, and EE. In adjusting the indicators revealed from the explorative studies 
above, the building performance indicators outlined in the ambitious Perfection project [29] and the Habitability framework by W. Preiser [30] were of particular influence. The first was an attempt towards a holistic measure of performance that used hard measurable data (such as temperature, noise etc.) as well as softer and subjective indicators (such as positive stimulation, usability etc.) organized in a tree-structure from general to specific. The Habitability Framework is Preiser's response to the challenge of capturing UD principles while avoiding a simple checklist approach.

Figure 6, adapted from O Shea, Pavia [31], shows UD assessment methods and how comfort indicators could relate to the universal design goals by Steinfeld and Maisel [9] and categories in the Habitability Framework by Preiser [30]. The table should not be interpreted as equivalence, but rather as terms describing similar things at different conceptual levels.

\begin{tabular}{|c|c|c|c|}
\hline UD Goals & & $\begin{array}{l}\text { Habitability } \\
\text { Framework }\end{array}$ & Comfort indicators \\
\hline \multirow{6}{*}{ Wellness } & \multirow{6}{*}{$\frac{\pi}{\bar{d}}$} & \multirow{4}{*}{ Health } & Light \\
\hline & & & Noise \\
\hline & & & Air Quality \\
\hline & & & Temperature \\
\hline & & Safety & Safety \\
\hline & & Security & Security \\
\hline \multirow{2}{*}{ Body Fit } & \multirow{7}{*}{$\frac{N}{d}$} & \multirow{2}{*}{ Functional } & Accessibility \\
\hline & & & Spaciousness \\
\hline \multirow{3}{*}{ Comfort } & & \multirow{3}{*}{ Efficiency } & Usability \\
\hline & & & Flexibility \\
\hline & & & Adaptability \\
\hline Awareness & & \multirow{2}{*}{ Workflow } & Intuitive Controls \\
\hline Understanding & & & Ease of Maintenance \\
\hline \multirow[b]{2}{*}{ Social integration } & \multirow{5}{*}{$\frac{m}{d}$} & Psychological & Views to outside \\
\hline & & Social & Social activity \\
\hline & & & Privacy \\
\hline & & & Identity \\
\hline Personalization & & Aesthetic & Elegance \\
\hline
\end{tabular}

Fig 6. A relative comparison of indicators adapted from O'Shea et al.

\subsection{A Framework for Comfort in the Indoor Environment}

As argued in section 2, a more accurate concept of IEQ would include both EE related and LLL aspects. The results from qualitative studies described in Section 3 indicate that comfort at home is made up of EE as well as LLL aspects. Otherwise stated, comfort indicators are also IEQ indicators.

Section 2 described how comfort is viewed in different disciplines - from the narrow focus on thermal comfort in traditional EE studies to the much wider physiological, 
sociological, psychological and cultural dimensions advocated in other disciplines. Although comfort is a very broad concept, the indicators of comfort according to residents in the context of home renovations are described in Section 4.1. Figure 6 makes it visible that comfort at home and UD are overlapping concepts since the comfort indicators fit within the goals of UD, although not vice-versa.

When brought together these ideas (comfort at home as combination of IEQ indicators, comfort at home as overlapping with UD goals, and comfort as a central objective of UD) reveal a concentric relationship between EE, IEQ, UD and Comfort. The relationships are illustrated in Figure 7. EE and LLL indicators are contained within IEQ/comfort at home, which is covered by most UD goals, and which in turn overlaps with aspects of a very broad concept of comfort.

For the purposes of our study on home renovations which include EE and LLL measures we focus on the wider set of IEQ indicators. In recognition of the fact that these indicators are also identified as contributing to comfort by residents, to acknowledge that they are a sub-section of a broader concept of comfort, and to differentiate from the narrow meaning of comfort and IEQ in Energy Efficiency literature, we can refer to them as indicators of Comfort in the Indoor Environment, or Indoor Environmental Comfort (IE Comfort).

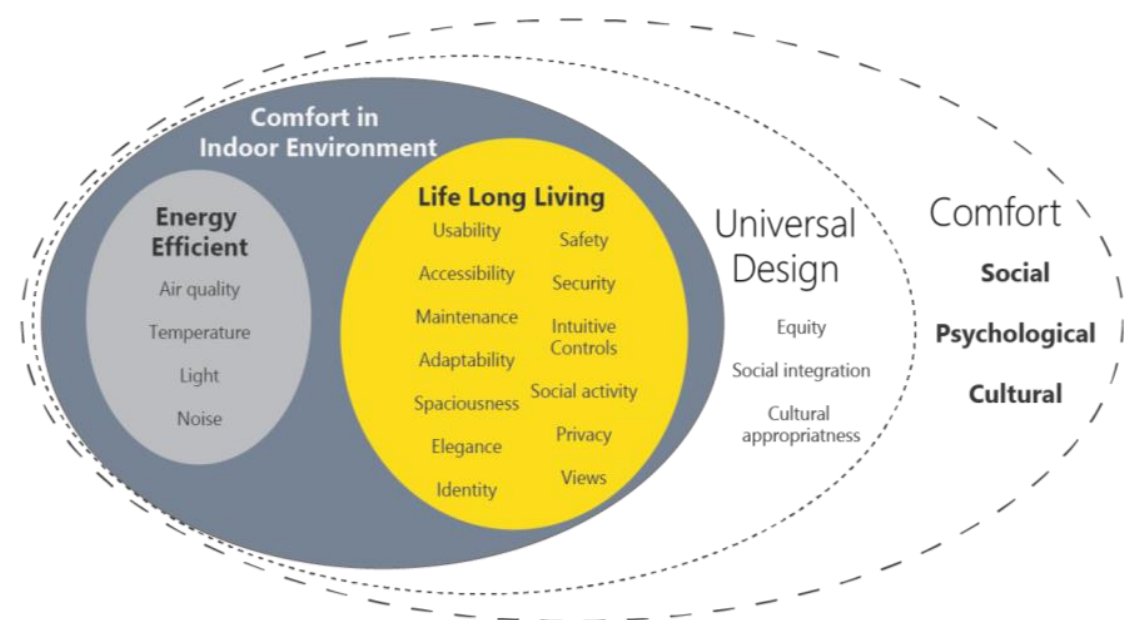

Fig. 7. Comfort in the Indoor Environment - constituted by Energy Efficiency related indicators as well as Universal Design indicators.

\section{Conclusion}

Results of the qualitative studies confirm that people associate with comfort all aspects related to EE such as temperature, air quality, light and noise, as well as with most key aspects in UD such as usability, accessibility, views to outdoors etc.. In addition they revealed that EE and UD aspects are not separate and unrelated but 
rather that EE, if considered from a comfort point of view, can be seen as a part of UD.

Framing discussions on EE and UD as part of comfort in the indoor environment as proposed in the framework above, implies a focus on the benefits of home renovation from the perspective of residents. It uses a language that can be more understandable and motivating for lay-people, while at the same time containing the core messages on EE and UD important to professionals, such as academics, policy makers, and designers. The framework attempts to bring together the individual objectives of people making decision on their home renovation with the objectives of professionals and society at large.

The presented theoretical framework for comfort in the indoor environment can be used to guide further study the synergetic merger of EE and UD fields in order to achieve higher adoption rates for both.

\section{References}

1. Kapedani, E., J. Herssens, and G. Verbeeck, Energy Efficiency and Universal Design in Home Renovations - A Comparative Review, in Universal Design 2016: Learning from the Past, Designing for the Future. 2016, IOS Press: York, UK. p. 324-334.

2. Aune, M., Making energy visible in domestic property markets: the influence of advertisements. Building Research \& Information, 2012. 40(6): p. 713-723.

3. Mills, E. and A. Rosenfeld, Consumer non-energy benefits as a motivation for making energy-efficiency improvements. Energy, 1996. 21(7-8): p. 707-720.

4. Bartiau, F., et al., Socio-technical factors influencing Residential Energy Consumption SEREC. 2006: Brussels, Belgium.

5. COHERENO, Customer segments and value propositions in the nZEB single-family housing renovation market, in COHERENO. 2014.

6. Shove, E., Comfort, cleanliness and convenience : the social organization of normality. New technologies/new cultures series. 2003, Oxford [etc.]: Berg.

7. Lindén, A.-L., A. Carlsson-Kanyama, and B. Eriksson, Efficient and inefficient aspects of residential energy behaviour: What are the policy instruments for change? Energy Policy, 2006. 34(14): p. 1918-1927.

8. Aune, M., M. Ryghaug, and Å. Godbolt. Comfort, consciousness and costs-transitions in Norwegian energy culture 1991-2010. Energy efficiency first: the foundation of a lowcarbon society. in Proceedings of the ECEEE. 2011.

9. Steinfeld, E. and J. Maisel, Universal design: Creating inclusive environments. 2012: John Wiley \& Sons.

10. Daninhirsch, H., Universal Design for Everyone - Safety, function and aesthetics should be part of the total design package for today's homeowners, in KBB. 2014. p. 44-46.

11. Rybczynski, W., Home: A short history of an idea. 1986: Viking New York.

12. Shove, E., et al., What Is Energy For? Social Practice and Energy Demand. Theory, Culture \& Society, 2014. 31(5): p. 41-58.

13. Reffat, R.M. and E.L. Harkness, Environmental comfort criteria: weighting and integration. Journal of performance of constructed facilities, 2001. 15(3): p. 104-108.

14. Frontczak, M. and P. Wargocki, Literature survey on how different factors influence human comfort in indoor environments. Building and Environment, 2011. 46(4): p. 922-937.

15. Bluyssen, P.M., M. Aries, and P. van Dommelen, Comfort of workers in office buildings: The European HOPE project. Building and Environment, 2011. 46(1): p. 280-288. 
16. Frontczak, M., R.V. Andersen, and P. Wargocki, Questionnaire survey on factors influencing comfort with indoor environmental quality in Danish housing. Building and Environment, 2012. 50: p. 56-64.

17. Schakib-Ekbatan, K., A. Wagner, and C. Lussac. Occupant satisfaction as an indicator for the socio-cultural dimension of sustainable office buildingsdevelopment of an overall building index. in Proceedings of Conference: Adapting to Change: New Thinking on Comfort. 2010.

18. Veitch, J.A., et al., A model of satisfaction with open-plan office conditions: COPE field findings. Journal of Environmental Psychology, 2007. 27(3): p. 177-189.

19. The Foundation for Lifetime Homes and Neighbourhoods. Lifetime Homes and inclusive design. 2016 [cited 2016 June 10]; Available from: http://www.lifetimehomes.org.uk/pages/introducing-.html.

20. Clarkson, P.J. and R. Coleman, History of Inclusive Design in the UK. Applied Ergonomics, 2015. 46, Part B: p. 235-247.

21. Kolcaba, K.Y. and R.J. Kolcaba, An analysis of the concept of comfort. Journal of advanced nursing, 1991. 16(11): p. 1301-1310.

22. Kolcaba, K., C. Tilton, and C. Drouin, Comfort theory: A unifying framework to enhance the practice environment. Journal of Nursing Administration, 2006. 36(11): p. 538-544.

23. Chappells, H. and E. Shove, Debating the future of comfort: environmental sustainability, energy consumption and the indoor environment. Building Research \& Information, 2005. 33(1): p. 32-40.

24. Shove, E., Converging Conventions of Comfort, Cleanliness and Convenience. Journal of Consumer Policy, 2003. 26(4): p. 395-418.

25. Cole, R.J., et al., Re-contextualizing the notion of comfort. Building Research \& Information, 2008. 36(4): p. 323-336.

26. Gram-Hanssen, K., Retrofitting owner-occupied housing: remember the people. Building Research \& Information, 2014. 42(4): p. 393-397.

27. Aune, M., Energy comes home. Energy Policy, 2007. 35(11): p. 5457-5465.

28. Tweed, C., Socio-technical issues in dwelling retrofit. Building Research \& Information, 2013. 41(5): p. 551-562.

29. Huovila, A., et al., A Generic Framework for Key Indoor Performance Indicators, in PERFECTION. 2010.

30. Preiser, W.F., The evolution of post-occupancy evaluation: Toward building performance and universal design evaluation. Learning From Our Buildings A State-of-the Practice Summary of Post-Occupancy Evaluation, 2001.

31. O Shea, E.C., et al., Measuring the design of empathetic buildings: a review of universal design evaluation methods. Disability and Rehabilitation: Assistive Technology, 2016. 11(1): p. 13-21. 